UDC 34.466 .3

LBC 67.304.1

\title{
THE INTEREST RATE UNDER THE CREDIT AGREEMENT IN THE LIGHT OF JUDICIAL PRACTICE
}

\author{
Irina E. Mikheeva \\ O.E. Kutafin Moscow State Law University (MSLA), Moscow, Russian Federation \\ Igor A. Ostapenko \\ Volgograd State University, Volgograd, Russian Federation
}

Introduction: the condition of the interest rate on the credit is material to the credit agreement. The civil legislation does not stipulate the requirements to the maximum interest rate under the credit agreement, which leads to the disputes in practice. The aim of the study is the legal precedents of applying the Russian legislation on interest under the credit agreement and changing the interest rate both by agreement of the Parties and unilaterally. Methods: the methodological framework for this study is a set of scientific methods, among which the main place is occupied by the method of analysis and the comparative law method. Results: grounded in the work the author's point of view is based on the legislation and judicial practice. The author concludes that the condition on the interest rate may be invalidated by the court if the interest rate is significantly different from the market conditions because of the disadvantageousness of such a condition.

The legal nature of the raised interest depends on what ground the interest rate was raised, which can serve as a liability or a new fee for the credit under certain conditions.

Conclusions: the law provides for the right of a credit institution to unilaterally raise the interest rate in cases stipulated in the contract, however, the newly established interest rate should be consistent with the principles of good faith and reasonableness; in addition, the bank has to prove the grounds for which it considers the possibility of the unilateral change of the interest rate.

Key words: interest rate, change of interest rate, credit institutions, borrowers, disadvantageousness, market conditions.

УДК 34.466 .3

ББК 67.304.1

\section{РАЗМЕР ПРОЦЕНТНОЙ СТАВКИ ПО КРЕДИТНОМУ ДОГОВОРУ В СВЕТЕ СУДЕБНОЙ ПРАКТИКИ}

\author{
Ирина Евгеньевна Михеева
}

\author{
Московский государственный юридический университет им. О.Е. Кутафина (МГЮА), \\ г. Москва, Российская Федерация
}

\section{Игорь Анатолиевич Остапенко}

Волгоградский государственный университет, г. Волгоград, Российская Федерация

\begin{abstract}
Введение: условие о размере процентов за пользование кредитом является существенным для кредитного договора. Гражданское законодательство не устанавливает требования к максимальному размеру процентной ставки по кредитному договору, что приводит к возникновению спорных ситуаций на практике. Целью исследования является судебная практика применения положений действующего российского законодательства о процентах по кредитному договору, изменении размера процентной ставки как по соглашению сторон, так и в одностороннем порядке. Методы: методологическую основу данного исследования составляет совокупность методов научного познания, среди которых основное место занимают методы анализа и сравнительно-правовой. Результаты: обоснованная в работе авторская позиция опирается на
\end{abstract}


законодательство и судебную практику. Автор делает вывод о том, что условие о размере процентной ставки может быть признано судом недействительным, если размер процентов значительно отличается от рыночных условий, по причине кабальности такого условия.

Правовая природа повышенных процентов зависит от основания, по которому осуществлено увеличение размера процентной ставки, которое может выступать как мера ответственности или новая плата за пользование кредитом при определенных условиях.

Выводы: законом предусмотрено право кредитной организации в одностороннем порядке увеличивать размер процентной ставки в случаях, предусмотренных договором, однако вновь установленная процентная ставка должна соответствовать принципам добросовестности и разумности, кроме того, банк должен доказать основания, с которыми связывает возможность одностороннего изменения размера процентов.

Ключевые слова: размер процентной ставки, изменение процентной ставки, кредитные организации, заемщики, кабальность, рыночные условия.

\section{Введение}

Размер процентов за пользование кредитом в соответствии со ст. 809,819 ГК РФ определяется по соглашению сторон кредитного договора.

При этом, как еще в начале прошлого века отмечал А.Э. Вормс, «размер договорных процентов законом не ограничен» (цит. по: [3, с. 23]). До настоящего времени «в современном российском гражданском законодательстве не предусматривается никаких ограничений максимального размера процентов и соответственно последствий установления высокого размера процентов» [4, с. 66].

Соответственно стороны кредитного договора могут договориться о любом максимальном размере процентной ставки за пользование кредитом. При этом, учитывая, что кредитные организации являются профессиональными участниками данных правоотношений, на практике возможны злоупотребления с их стороны.

Несмотря на отсутствие в законодательстве прямых ограничений размера процентов, в последние годы в судебной практике выработалась позиция о том, что размер процентной ставки по кредитному договору должен быть согласован с учетом рыночного значения размера процентной ставки.

\section{Требования к рыночному размеру процентной ставки}

Процентная ставка должна устанавливаться с учетом рыночных условий, как указал Пленум Верховного Суда Российской Федерации в абз. 2 п. 14 Постановления от 22 ноября 2016 г. № 54 «О некоторых вопросах при- менения общих положений Гражданского кодекса Российской Федерации об обязательствах и их исполнении» (далее - Постановление ВС РФ № 54). При несоблюдении данного требования кредитными организациями существует риск отказа им во взыскании превышающей ее части процентов в судебном порядке.

Процентная ставка, размер которой существенно отличается от рыночной ставки, может свидетельствовать об установлении крайне невыгодных условий данного договора для истца (заемщика) и кабальности кредитного договора. Кабальная сделка может быть признана недействительной.

В Информационном письме Президиума ВАС РФ от 10 декабря 2013 г. № 162 «Обзор практики применения арбитражными судами статей 178 и 179 Гражданского кодекса Российской Федерации» был сделан вывод о применении положений о кабальности сделки к гражданам, осуществляющим предпринимательскую деятельность без образования юридического лица, несмотря на то что характер их деятельности, так же как и у коммерческих организаций, связан с предпринимательским риском. Как указал суд, «в соответствии со статьей 179 ГК РФ к элементам состава, установленного для признания сделки недействительной как кабальной, относится заключение сделки на крайне невыгодных условиях, о чем может свидетельствовать, в частности, чрезмерное превышение цены договора относительно иных договоров такого вида. Вместе с тем наличие этого обстоятельства не является обязательным для признания недействительной сделки, совершенной под влиянием обмана, насилия, угрозы или злонамеренного соглашения представителя одной стороны с другой стороной. 
Удовлетворяя исковое требование, суд исходил из того, что представленные истцом доказательства подтверждают факт стечения тяжелых обстоятельств на стороне истца. При этом судом было отмечено, что в совокупности размер процентов по спорному договору займа, чрезмерно отличающийся от процентных ставок по заключаемым договорам того же типа, и его срок свидетельствуют об установлении крайне невыгодных условий данного договора для истца (заемщика). Более того, размер процентной ставки по спорному договору настолько превышал среднюю процентную ставку, сложившуюся на рынке кредитования для договоров займа с аналогичными условиями (не более 30-40 процентов годовых), что совокупность названных обстоятельств в достаточной степени свидетельствует о кабальности указанного договора. < .. >. Суд подчеркнул, что наличие у истца статуса индивидуального предпринимателя не означает, что на него не распространяются установленные законом гарантии защиты имущественных интересов участников гражданского оборота, в том числе и при совершении сделок на крайне невыгодных условиях. <...>».

Спорный договор займа был признан судом недействительным на основании ст. 179 ГК РФ.

\section{Порядок изменения размера процентной ставки}

Изменение размера процентной ставки по кредитному договору осуществляется по общим правилам, установленным ГК РФ об изменении договора, с учетом специальных положений, предусмотренных законом для кредитного договора.

Согласно п. 1 ст. 450 ГК РФ изменение договора возможно по соглашению сторон, если иное не предусмотрено ГК РФ, другими законами или договором.

Изменение процентной ставки по соглашению сторон, как правило, не вызывает на практике спорных ситуаций.

\section{Изменение размера процентной ставки в одностороннем порядке}

Общие требования к порядку одностороннего изменения обязательств установле- ны п. 2 ст. 310 ГК РФ, предусматривающим основания для такого изменения, в зависимости от характера деятельности сторон договора (предпринимательский, личный).

Поскольку изменение размера процентной ставки в одностороннем порядке является односторонним изменением обязательства, к порядку такого изменения применяются правила п. 2 ст. 450.1 ГК РФ, предусматривающие, что в случае одностороннего отказа от договора (исполнения договора) полностью или частично, если такой отказ допускается, договор считается расторгнутым или измененным.

Как разъяснил ВС РФ, в п. 13 Постановления ВС РФ № 54 в силу п. 1 ст. 450.1 ГК РФ право на одностороннее изменение условий договорного обязательства или на односторонний отказ от его исполнения может быть осуществлено управомоченной стороной путем соответствующего уведомления другой стороны. Договор изменяется или прекращается с момента, когда данное уведомление доставлено или считается доставленным по правилам ст. 165.1 ГК РФ, если иное не предусмотрено ГК РФ, другими законами, иными правовыми актами или условиями сделки либо не следует из обычая или из практики, установившейся во взаимоотношениях сторон».

Наиболее спорными в правоприменении являются ситуации, связанные с увеличением процентной ставки, что и будет рассмотрено более подробно.

Как уже было отмечено, увеличение процентной ставки по кредитному договору возможно только с заемщиками, являющимися субъектами предпринимательской деятельности, и невозможно с гражданами-потребителями.

Решение вопроса о соотношении процентов по денежному обязательству и процентов как меры ответственности за неисполнение денежного обязательства определяется различием в правовой сущности тех и других процентов [2, с. 16].

Правовая природа увеличенной процентной ставки по кредитному договору в случае неисполнения заемщиком обязательства определяется с учетом характера допущенного заемщиком нарушения, которые можно разделить на два основания: за возникнове- 
ние просроченной задолженности по кредиту (основному долгу); за все иные нарушения, за которые кредитным договором предусмотрено увеличение размера процентной ставки.

Проанализируем более подробно указанные основания увеличения размера процентной ставки по кредитному договору.

Согласно ст. 811 ГК РФ, если иное не предусмотрено законом или договором займа, в случаях, когда заемщик не возвращает в срок сумму займа, на эту сумму подлежат уплате проценты в размере, предусмотренном п. 1 ст. 395 ГК РФ, со дня, когда она должна была быть возвращена, до дня ее возврата займодавцу независимо от уплаты процентов, предусмотренных п. 1 ст. 809 ГК РФ.

Вопрос о правовой природе процентов, увеличенных в связи с возникновением просроченной задолженности по кредиту, длительное время оставался спорным в банковской практике.

Однако суды неоднократно отмечали, что повышение процентной ставки при возникновении просроченной задолженности является видом гражданско-правовой ответственности за нарушение обязательств. Так, в п. 15 Постановления Пленума Верховного Суда РФ № 13, Пленума ВАС РФ № 14 от 8 октября 1998 г. «О практике применения положений Гражданского кодекса Российской Федерации о процентах за пользование чужими денежными средствами» дано разъяснение, что «в тех случаях, когда в договоре займа либо в кредитном договоре установлено увеличение размера процентов в связи с просрочкой уплаты долга, размер ставки, на которую увеличена плата за пользование займом, следует считать иным размером процентов, установленных договором в соответствии с пунктом 1 статьи 395 Кодекса».

Процентная ставка за незаконное пользование денежными средствами в силу ст. 395 ГК РФ может рассчитываться исходя из ключевой ставки Банка России, действовавшей в соответствующие периоды при отсутствии иного соглашения сторон, либо в размере ставки, на которую увеличена процентная ставка, предусмотренной соглашением сторон.

Вместе с тем в литературе высказывалась также позиция о том, что проценты, начисленные при возникновении просроченной задолженности по основному долгу, в свете судебных разъяснений могут являться как мерой ответственности (ст. 395 ГК РФ), так и обычными процентами за пользование заемными средствами, только измененными под условием невозврата займа в установленный срок. Повышение процентов следует рассматривать как изменение процентной ставки за пользование суммой займа при наступлении определенного условия - просрочки возврата суммы займа. В связи с этим повышенные проценты подлежат включению в основную сумму задолженности [1, с. 10].

Однако данная позиция представляется неубедительной, поскольку в ст. 811 ГК РФ предусмотрено начисление процентов при возникновении просроченной задолженности по ст. 395 ГК РФ.

В тех случаях, когда увеличение процентной ставки в кредитном договоре предусмотрено за неисполнение обязательств со стороны заемщика (за исключением возникновения просроченной задолженности по кредиту), измененная в одностороннем порядке процентная ставка является платой за пользование кредитом, если иное не предусмотрено кредитным договором.

Данная позиция неоднократно высказывалась судебными органами.

Президиум ВАС РФ в п. 13 Информационного письма Президиума ВАС РФ от 13 сентября 2011 г. № 147 «Обзор судебной практики разрешения споров, связанных с применением положений Гражданского кодекса Российской Федерации о кредитном договоре» установил, что «суд взыскал задолженность по кредитному договору, содержащему условие о повышении размера процентов в случае ухудшения обеспечения кредита, а также уменьшения определенных в договоре показателей финансово-хозяйственной деятельности заемщика, повышенные проценты в полном объеме, установив, что произошла утрата обеспечения исполнения обязательств по договору, а новое обеспечение не предоставлено. <..> условие о повышении процентов в данном случае не может рассматриваться как условие об ответственности за нарушение обязательства по возврату кредита...».

Таким образом, увеличенная процентная ставка за нарушения, отличные от возникно- 
вения просроченной задолженности по основному долгу (кредиту), если иное не предусмотрено соглашением сторон, будет являться новым размером процентов за пользование кредитом.

При увеличении процентной ставки по кредитным договорам должны учитываться требования ст. 10 ГК РФ, то есть кредитор не должен нарушать разумный баланс прав и обязанностей сторон либо иным образом нарушать основополагающие частноправовые принципы разумности и добросовестности, что неоднократно отмечалось в судебных постановлениях.

Проиллюстрируем данный вывод на конкретном судебном деле.

Президиум ВАС РФ, рассматривая дело № A71-10080/2010-Г33, в Постановлении № 13567/11 от 6 марта 2012 г. указал следующее: «<..> при реализации предусмотренного кредитным договором права в одностороннем порядке изменять условия кредитования банк должен действовать в допустимых пределах осуществления гражданских прав и доказать наличие оснований, с которыми по условиям договора связана возможность одностороннего изменения банком размера платы (процентов) за кредит.

Право банка на одностороннее изменение процентной ставки по кредиту, закрепленное в договоре, не означает, что заемщик, не согласный с такими изменениями, не может доказать, что одностороннее изменение договорных условий нарушает разумный баланс прав и обязанностей сторон, противоречит устоявшимся деловым обыкновениям либо иным образом нарушает основополагающие частноправовые принципы разумности и добросовестности».

Аналогичная позиция была высказана ВС РФ, который в п. 14 Постановления ВС РФ № 54 указал, что «при осуществлении стороной права на одностороннее изменение условий обязательства или односторонний отказ от его исполнения она должна действовать разумно и добросовестно, учитывая права и законные интересы другой стороны (п. 3 ст. 307, п. 4 ст. 450.1 ГК РФ).

Например, по этому основанию суд отказывает во взыскании части процентов по кредитному договору в случае односторонне- го, ничем не обусловленного непропорционального увеличения банком процентной ставки».

Следует также учитывать, что банк должен доказать основания, с которыми связывает возможность одностороннего изменения размера процентов.

\section{Выводы}

Размер процентов по кредитному договору не должен чрезмерно отличаться от процентных ставок по заключаемым договорам, то есть обязан соответствовать рыночным условиям.

Условие о размере процентной ставки, существенно отличающемся от рыночной ставки, может свидетельствовать о кабальности кредитного договора.

При увеличении процентной ставки по кредитному договору должны учитываться требования ст. 10 ГК РФ, то есть кредитор не должен нарушать разумный баланс прав и обязанностей сторон либо иным образом нарушать основополагающие частноправовые принципы разумности и добросовестности.

Изменение банком процентной ставки по кредитному договору в одностороннем порядке может быть признано судом недействительным в том случае, если будет доказано, что действия банка нарушают общий баланс интересов сторон, противоречат принципам разумности и добросовестности (ст. 1, 10 ГК РФ), в том числе о рыночных условиях процентной ставки, либо заемщик был поставлен в условия, которые не позволяли ему исполнить обязательство надлежащим образом.

Последствиями необоснованного увеличения процентной ставки в одностороннем порядке при нарушении принципов добросовестности и разумности являются отказ во взыскании части процентов по кредитному договору; признание недействительными спорных договорных условий, в том числе по правилам ст. 428 ГК РФ.

\section{СПИСОК ЛИТЕРАТУРЫ}

1. Дубровская, И. Правовая природа повышенных процентов / И. Дубровская // ЭЖ-Юрист. 2013. - № 38. - C. 1.

2. Егорова, М. А. Проценты по денежному обязательству: краткий комментарий статьи 317.1 
ГК РФ / М. А. Егорова, К. М. Арсланов // Вестник арбитражной практики. - 2017. - № 1. - С. 15-21.

3. Очерки кредитного права / под ред. А. Э. Вормса. - М. : Финансовое изд-воНКФ СССР, 1926.-167 с.

4. Чхутиашвили, Л. В. Актуальные вопросы регулирования кредитного договора по российскому праву / Л. В. Чхутиашвили // Банковское право. -2012 . - № 1. - С. 65-68.

\section{REFERENCES}

1. Dubrovskaya I. Pravovaya priroda povyshennykh protsentov [The Legal Nature of Increased Interest]. EZh-Yurist, 2013, no. 38, p. 1.
2. Egorova M.A., Arslanov K.M. Protsenty po denezhnomu obyazatelstvu: kratkiy kommentariy statyi 317.1 GK RF [Interest on the Monetary Obligation: a BriefCommentary on Article 317.1 of the Civil Code of the Russian Federation]. Vestnik arbitrazhnoy praktiki, 2017, no. 1, pp. 15-21.

3. Vorms A.E., ed. Ocherki kreditnogo prava [Sketches of Credit Law]. Moscow, Finansovoe izd-vo NKF SSSR, 1926. 167 p.

4. Chkhutiashvili L.V. Aktualnye voprosy regulirovaniya kreditnogo dogovora po rossiyskomu pravu [Current Issues of Regulation of a Loan Agreement on Russian Law]. Bankovskoe pravo, 2012, no. 1 , pp. 65-68.

\section{Information about the Authors}

Irina E. Mikheeva, Candidate of Juridical Sciences, Associate Professor, Deputy Head of the Department of Banking Law, O.E. Kutafin Moscow State Law University (MSLA), SadovayaKudrinskaya St., 9, 125993 Moscow, Russian Federation, Ya.miheeva@yandex.ru.

Igor A. Ostapenko, Postgraduate Student, Department of Civil and International Private Law, Volgograd State University, the Base Department of the Southern Scientific Center of the Russian Academy of Sciences, Prosp. Universitetsky, 100, 400062 Volgograd, Russian Federation, gimchp@volsu.ru.

\section{Информация об авторах}

Ирина Евгеньевна Михеева, кандидат юридических наук, доцент, заместитель заведующего кафедрой банковского права, Московский государственный юридический университет им. О.Е. Кутафина (МГЮА), ул. Садовая-Кудринская, 9, 125993 г. Москва, Российская Федерация, Ya.miheeva@yandex.ru.

Игорь Анатолиевич Остапенко, аспирант кафедры гражданского и международного частного права, Волгоградский государственный университет, базовая кафедра ЮНЦ РАН, просп. Университетский, 100, 400062 г. Волгоград, Российская Федерация, gimchp@volsu.ru. 